\title{
Síndrome de Parsonage-Turner
}

\author{
Parsonage-Turner syndrome
}

Luis Gerardo Domínguez Gasca, ${ }^{*}$ Jorge Ignacio Magaña Reyes, ${ }^{\ddagger}$ Luis Gerardo Domínguez Carrillo§

Citar como: Domínguez GLG, Magaña RJI, Domínguez CLG . Síndrome de Parsonage-Turner. Acta Med. 2021; 19 (1): 132-133. https://dx.doi.org/10.35366/98585

Masculino de 46 años, profesionista, deportista, como antecedente de importancia sufrió cuadro de influenza 15 días antes, acude por cuatro días de dolor en hombro y brazo derecho, sin antecedente de traumatismo previo, de dolor intenso con calificación 9/10 en EVA, de irradiación en territorio $\mathrm{C} 5$ derecho. A la exploración, arcos de movimiento completos tanto activos como pasivos, con fuerza muscular 4/5 por dolor, para músculos de hombro derecho y $5 / 5$ para el contralateral, reflejos tricipital, bicipital y estilorradial normales, pulsos y llenado capilar normales. Con el diagnóstico presuntivo de compresión radicular
C5 derecho se solicitó resonancia magnética (RM) de columna cervical, la cual fue reportada como normal; se solicitó RM de hombros, en la que se observaron cambios crónicos de artrosis, llamando la atención el incremento de señal en músculos subescapular e infraespinoso por edema al compararse con lado contralateral, por lo que se diagnosticó síndrome de Parsonage-Turner. Se manejó con prednisona a dosis inicial de $1 \mathrm{mg} / \mathrm{kg}$, disminuyendo dosis en 10 días, gabapentina a dosis inicial de 300 mg dos veces al día, incrementando $600 \mathrm{mg}$ dos veces al día, el dolor disminuyó a 3/10, presentando paresia de músculos
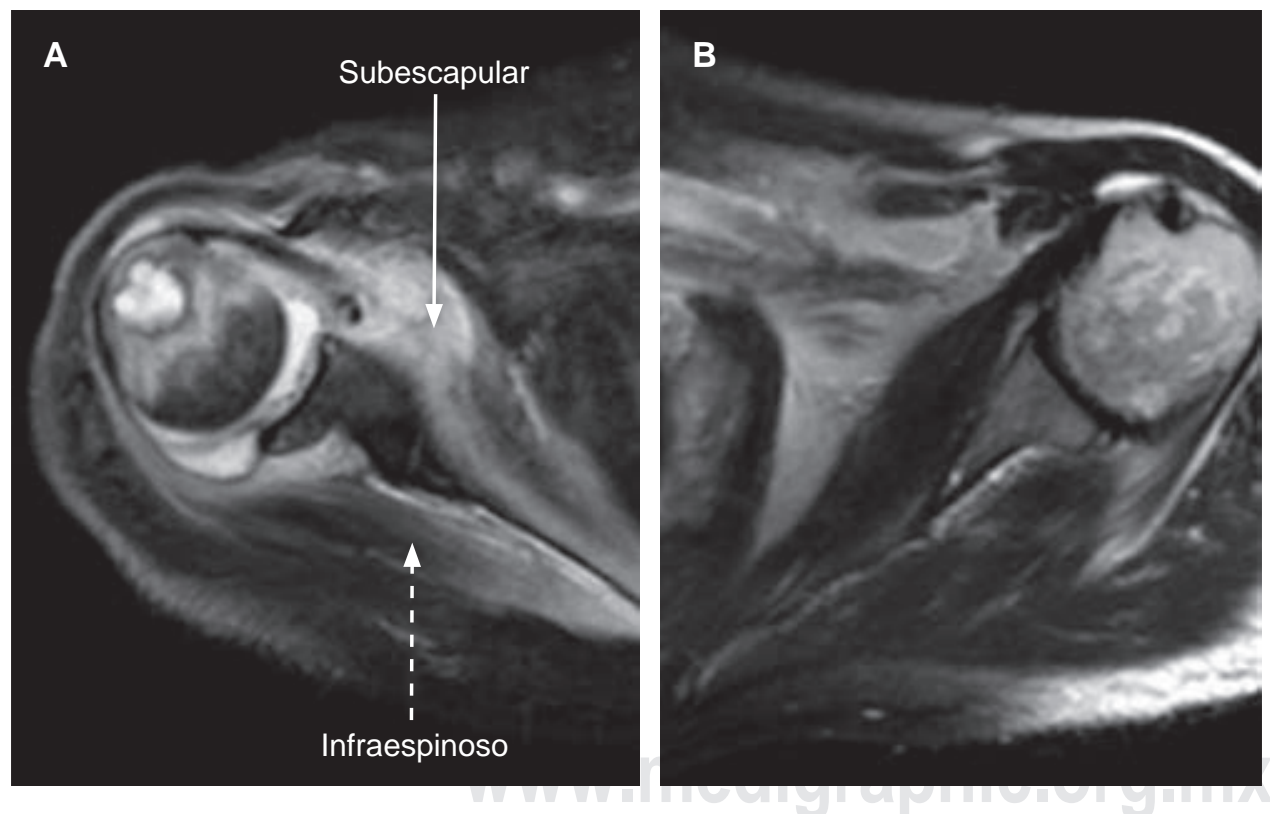

Figura 1:

Imágenes de resonancia magnética de ambos hombros, las cuales muestran en (A) articulación glenohumeral derecha con superficie irregular por erosión marginal subcondral de margen en la cabeza humeral derecha adyacente al troquíter, presencia de líquido y cambios de esclerosis de hueso subcondral en cabeza humeral e incremento de señal en músculos subescapular e infraespinoso por edema al compararse con lado contralateral en (B).

\footnotetext{
* Ortopedista. Cirujano Articular. División de Cirugía del Hospital Ángeles León. León, Guanajuato, México.

₹ Imagenólogo. Hospital Villas del Campestre. León, Guanajuato, México.

$\S$ Especialista en Medicina de Rehabilitación. Catedrático de la Facultad de Medicina de León, Universidad de Guanajuato. México.
}

\section{Correspondencia:}

Acad. Dr. Luis Gerardo Domínguez Carrillo

Correo electrónico: Igdomínguez@hotmail.com

Aceptado: 06-02-2020. 
de hombro con calificación 3/5 en escala de Daniels. Se canalizó al paciente a rehabilitación.

El síndrome de Parsonage-Turner ${ }^{1}$ (SPT) o plexitis braquial fue mencionada inicialmente por Feinberg en 1897 en un caso asociado con influenza, es una neuritis del tronco superior del plexo braquial; Parsonage y Turner $^{2}$ la describieron en 1948 en 136 soldados y posteriormente en 82 pacientes; es bilateral en $25 \%$ de los casos, con incidencia de 1.5 casos/100,000, principalmente en varones entre la tercera y quinta década de la vida. Esta enfermedad es de etiología desconocida, se ha descrito asociación con factores desencadenantes (coexiste en ocasiones con procesos inmunes). De manera inicial se manifiesta con una fase de dolor agudo y súbito en hombro irradiado a la extremidad; posteriormente se presenta paresia que llega a parálisis (fase de parálisis y amiotrofia) del deltoides, supraespinoso, infraespinoso y/o serrato anterior; le sigue una etapa de recuperación que suele durar entre seis meses y un año, por lo general no deja secuelas en $75 \%$ de los casos. Es una enfermedad rara que debe ser parte del diagnóstico diferencial en cuadros de dolor en región proximal de miembros superiores cuando se asocian síntomas o signos neuromusculares. Se han descrito cuadros de amiotrofia neurálgica o del plexo braquial con carácter hereditario y transmisión autosómica dominante afectando al cromosoma 17 (17p25). ${ }^{3}$ La resonancia magnética es el estudio de elección, los datos observables son la aparición de señales hiperintensas en los músculos supraespinoso, infraespinoso y subescapular, que se interpretan como derivados del edema muscular secundario a la denervación (Figura 1). ${ }^{4}$ El tratamiento es sintomático con analgésicos, fisioterapia y rehabilitación.

\section{REFERENCIAS}

1. Briceño PF, Rodríguez MS. Síndrome de Parsonage-Turner. Revisión bibliográfica. Sem Fund Esp Reumat. 2010; 11 (4): 144-151.

2. Parsonage MJ, Turner JW. Neuralgic amyotrophy; the shoulder-girdle syndrome. Lancet. 1948; 1 (6513): 973-978.

3. Kuhlenbäumer G, Meuleman J, De Jonghe P, Falck B, Young P, Hünermund G et al. Hereditary Neuralgic Amyotrophy (HNA) is genetically heterogeneous. J Neurol. 2001; 248 (10): 861-865.

4. Scalf RE, Wenger DE, Frick MA, Mandrekar JN, Adkins MC. MRI findings of 26 patients with Parsonage-Turner syndrome. AJR. 2007; 189: W39-W44. 